\title{
Macrofauna edáfica em cultivo de palma forrageira no período seco e chuvoso no Seridó Potiguar ${ }^{1}$
}

\author{
Flaviano Fernandes de Oliveira ${ }^{2}$, José Thyago Aires Souza ${ }^{3}$, Mileny dos Santos de Souza ${ }^{4}$, \\ Lourival Ferreira Cavalcante ${ }^{5}$, Guilherme Ferreira da Costa Lima ${ }^{6}$, Jacinto de Luna Batista ${ }^{7}$
}

Resumo: A macrofauna do solo constitui-se em uma eficaz ferramenta de bioindicação da qualidade edáfica em áreas cultivadas, inclusive com palma forrageira, que pela sua adaptabilidade caracteriza-se como elemento biológico compatível às condições semiáridas. Neste contexto, objetivou-se caracterizar a macrofauna edáfica em cultivo de Nopalea cocholenifera Salm Dyck em diferentes épocas no Seridó Potiguar. A pesquisa foi conduzida na EMPARN, município de Cruzeta, estado do Rio Grande do Norte, Brasil, de dezembro de 2016 a janeiro de 2017 (Época seca) e de março a abril de 2017 (Época chuvosa). O experimento foi realizado em delineamento inteiramente casualizado com cinco repetições. Utilizaram-se armadilhas do tipo Provid, enterradas aleatoriamente na área de modo que as aberturas situassem - se ao nível da superfície do solo durante quatro semanas. As coletas foram realizadas semanalmente em cinco pontos da área para cada época. Após a quantificação dos indivíduos, calculou-se a riqueza pelo número de ordens, os índices de frequência, abundância, dominância e constância utilizando o software ANAFAU e também os índices de diversidade de Shannon (H) e uniformidade de Pielou (e). No somatório das coletas identificaram-se 4.160 indivíduos na época da estiagem, distribuídos em dez ordens e na época chuvosa obtiveram-se 1.779 pertencentes a quinze ordens. Constatou-se que a macrofauna no cultivo de palma forrageira é mais abundante na época da estiagem, entretanto é mais diversa na época chuvosa.

Palavras-chave: Sazonalidade; Fauna do solo; Nopalea cocholenifera; Cultivo de xerófilas.

\section{Macrofauna edaphicum in forage palm cultivation in the dry and rainy season in Seridó Potiguar}

\begin{abstract}
The soil macrofauna constitutes an effective tool of bioindication of edaphicquality in cultivated areas, including forage spineless cacti, which by its adaptability characterizes itself as biological element compatible with semi-arid conditions. In this context, the objective was to characterize the edaphic macrofauna in cultivation of Nopalea cocholenifera Salm Dyck at different periods in region from Seridó Potiguar. The research was conducted in EMPARN, municipality of Cruzeta, Rio Grande do Norte State, Brazil, during the December/2016 to January/2017 (dry period) and from March to April/2017 (rainy period). The experiment was carried out in a completely randomized design with five replicates. Traps of the Provid type were used, where they were randomly buried in the areas o that the openings were at the level of the soil surfacefor a period of four weeks. The collections were carried out weekly in five points of the area for each season. After quantification of the individuals, we calculated the wealth (number of groups identified), the frequency, abundance, dominance and constancy indexes, obtained through software ANAFAUand also the diversity indexes of Shannon $(\mathrm{H})$ and uniformity of Pielou (e). In the sum of the collections, 4,160 individuals were identified during the dry season, distributed in ten orders and in rainy season 1,779 were obtained, belonging to fifteen orders. It was verified that the macrofauna in the cultivation of forage spineless cacti is more abundantin the dry season, however it is more diverse in the rainy season.
\end{abstract}

Keywords: Seasonality; soil fauna; Nopalea cocholenifera; cultivation of xerophiles.

\footnotetext{
${ }^{1}$ Submetido em 12/04/2018 e aprovado em 09/05/2018

${ }^{2}$ Graduando em Agronomia, Universidade Federal da Paraíba (UFPB), Centro de Ciências Agrárias, Areia - Paraíba, CEP: 58.397-000; Email: flavianoufpb@gmail.com

${ }^{3}$ Mestre em Agronomia; Doutorando, Universidade Federal da Paraíba (UFPB), Centro de Ciências Agrárias, Programa de Pós-Graduação em Agronomia, Areia - Paraíba, CEP: 58.397-000; E-mail: thyagotaperoa@ hotmail.com.

${ }^{4}$ Mestre em Agronomia; Doutoranda, Universidade Federal da Paraíba (UFPB), Centro de Ciências Agrárias, Programa de Pós-Graduação em Agronomia, Areia - Paraíba, CEP: 58.397-000; E-mail: mileny.lopes67@ gmail.com.

${ }^{5}$ Doutorado em Solos e Nutrição de Plantas; Professor Universidade Federal da Paraíba (UFPB), Centro de Ciências Agrárias, Programa de Pós-Graduação em Agronomia, Areia - Paraíba, CEP: 58.397-000; E-mail: lofeca@cca.ufpb.br

${ }^{6} \mathrm{Ph} . \mathrm{D}$ em Agronomy; Pesquisador, Empresa de Pesquisa Agropecuária do Rio Grande do Norte, Natal - Rio Grande do Norte, CEP: 59.062500; E-mail: guilhermeemparn@ @n.gov.br

${ }^{7}$ Doutor em Agronomia; Professor, Universidade Federal da Paraíba (UFPB), Centro de Ciências Agrárias, Areia - Paraíba, CEP: 58.397-000 E-mail: jacinto@cca.ufpb.br.
}

Revista Agropecuária Técnica, Areia-PB, v. 39, n. 2, p. 143-150, 2018

DOI: https://doi.org/10.25066/agrotec.v39i2.39148 


\section{Introdução}

O cultivo de plantas xerófilas é extremamente compatível com as condições ecológicas do semiárido brasileiro, nesse sentido a palma forrageira (Nopalea cocholenifera Salm Dyck) destaca-se como uma das plantas de maior potencial produtivo, sendo utilizada para o arraçoamento dos rebanhos bovinos, caprinos e ovinos, principalmente nas épocas de estiagem (Galvão Júnior et al., 2014).

Os baixos índices pluviométricos, associados à descontinuidade de precipitação, com chuvas convectivas, ou seja, de alta intensidade e curta duração, tornam longos os processos naturais do solo no semiárido brasileiro (Ramos et al., 2017). Nesta região, os fatores biológicos do solo se tornam ainda mais importantes, principalmente em áreas cultivadas, pela intensificação da dinâmica edáfica, auxiliando na manutenção do sistema solo-planta em níveis produtivos adequados (Correia e Oliveira, 2006).

A macrofauna edáfica tem sido apontada como um eficiente indicador da qualidade do solo, além da expressiva sensibilidade às mudanças ambientais (Marques et al., 2014), estes organismos são fundamentais ao solo, tanto pela fragmentação dos resíduos orgânicos, aumentando assim a área superficial para a atividade microbiana, como pela produção de enzimas responsáveis pela quebra de biomoléculas complexas em compostos mais simples, auxiliando na formação do húmus (Aita et al., 2014).

Balin et al. (2017) afirmam que além de intensificarem os processos biológicos, os integrantes da macrofauna edáfica influenciam positivamente nas propriedades físicas e químicas do solo. As galerias construídas e as excreções fecais dos organismos modificam o espaço poroso, exercendo importante papel na aeração e na permeabilidade do solo, enquanto que, os bioporos também contribuem para o crescimento das raízes reduzindo a resistência mecânica do solo (Martins et al., 2017).

$\mathrm{Na}$ região semiárida, fatores diversos de ordem natural regulam a estrutura e abundância da comunidade edáfica ao longo do ano, entre eles o clima, o qual pode influenciar o padrão de distribuição e diversidade de muitos grupos biológicos (Almeida et al., 2015). Simpson et al. (2012) ressaltam que na avaliação da fauna edáfica como indicador de qualidade de um agroecossistema, a variabilidade temporal da quantidade e diversidade de biomassa, deve ser observada, pois a população dos indivíduos é dependente do período do ano conforme variações de luminosidade, temperatura e umidade edáfica e do ar. Diante do exposto, objetivou-se caracterizar a macrofauna edáfica em solo cultivado com palma forrageira em diferentes épocas do ano no Seridó Potiguar.

\section{Material e Métodos}

O experimento foi realizado na Estação Experimental da Empresa Estadual de Pesquisa Agropecuária do Rio Grande do Norte, EMPARN, localizada em Cruzeta-RN, microrregião Seridó Oriental nas coordenadas $6^{\circ} 24^{\prime} 42^{\prime \prime} \mathrm{S}$ e $36^{\circ} 47^{\prime} 22^{\prime}$ ' $\mathrm{W}$ com altitude de $232 \mathrm{~m}$. O clima da região, segundo a classificação de Köppen, é do tipo Bsh' (Alvares et al., 2013), com chuvas de janeiro a abril, apresentando temperaturas médias anuais entorno de $27^{\circ} \mathrm{C}$, umidade relativa do ar em torno de $50 \%$, com precipitações médias de $580 \mathrm{~mm}$ anuais. Os dados climatológicos quanto à precipitação, temperatura mínima e máxima e umidade relativa do ar durante o período experimental se encontram na Figura 1.

A pesquisa foi realizada em uma área cultivada com palma forrageira (Nopalea cocholenifera) sob espaçamento de 1,0 entre linhas e $0,25 \mathrm{~m}^{-1}$ entre plantas, que corresponde à densidade de 40.000 plantas ha $^{-1}$. A irrigação foi realizada quinzenalmente através da aplicação de uma lâmina de $2 \mathrm{~L}$ por metro linear via gotejamento convencional, com o sistema trabalhando sob uma pressão de serviço de 0,2 MPa. Utilizou-se fita gotejadora com $15 \mathrm{~mm}$ de diâmetro nominal e vazão de $5 \mathrm{~L} \mathrm{~h}^{-1} \mathrm{~m}^{-1}$, com espaçamento entre os gotejadores de $30 \mathrm{~cm}$. O delineamento experimental foi inteiramente casualizado e os tratamentos referiram-se ao período da estiagem e chuvoso com cinco repetições. A adubação foi realizada de acordo com as recomendações de Santos et al. (2008).

O método utilizado para a coleta dos indivíduos da macrofauna foi o Provid (Antoniolli et al., 2006), constituído por recipientes PET transparentes com capacidade para $2 \mathrm{~L}$, com uma abertura de $2 \mathrm{~cm}^{2}$ em cada quadrante à $20 \mathrm{~cm}$ da base, totalizando quatro

Revista Agropecuária Técnica, Areia-PB, v. 39, n. 2, p. 143-150, 2018

DOI: https://doi.org/10.25066/agrotec.v39i2.39148 
aberturas. Em seguida as armadilhas foram preenchidas com $200 \mathrm{~mL}$ de uma solução aquosa de detergente neutro a $10 \%$ e cinco gotas de formaldeído a $20 \%$, ambos com o objetivo respectivo de capturar e conservar os espécimes.
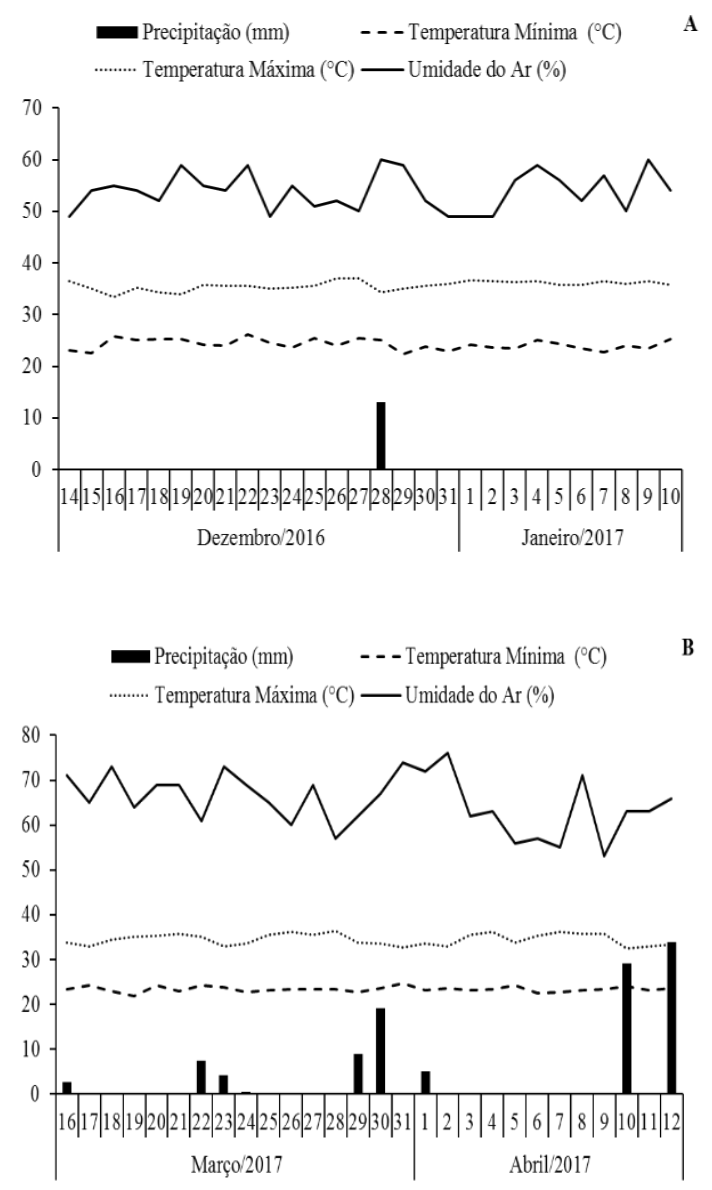

Figura 1 Precipitação, temperatura mínima e máxima e umidade relativa do ar durante o período experimental na época da estiagem (A) e chuvosa (B).

As armadilhas foram distribuídas aleatoriamente, de modo que as aberturas ficassem ao nível da superfície edáfica em cinco pontos da área por quatro semanas em cada época, de dezembro de 2016 a janeiro de 2017 (período da estiagem) e de março a abril de 2017 (período chuvoso), sendo as coletas realizadas de forma semanal. Após cada coleta os organismos foram acondicionados em recipientes específicos para o transporte com uma solução de álcool etílico a 70 $\%$, sendo em seguida levados para o Laboratório de Entomologia da Universidade Federal da Paraíba, Campus II, Areia, PB, para contagem e identificação em placas de petri com o auxílio de pinças, para visualização de suas estruturas, utilizou-se um microscópio estereoscópico.

Os indivíduos foram classificados com uso de literatura especializada ao nível de ordem, sendo obtido, além do número total de indivíduos, os índices de dominância, abundância, frequência e constância, calculados através do software ANAFAU (Silveira Neto et al., 2005). A Dominância (D) é a ação efetivada pelos organismos dominantes de uma comunidade, consistindo na capacidade da espécie em alterar, em benefício próprio o impacto recebido do ambiente, podendo resultar no aparecimento ou desaparecimento de outros organismos, mensurada através do método de Laroca e Mielke (1975), onde, $\mathrm{ND}=$ não dominante; $\mathrm{D}=$ dominante e $\mathrm{SD}=$ superdominante. $\mathrm{A}$ Abundância (S) corresponde ao número de indivíduos por unidade de superfície ou volume e varia no espaço e no tempo, sendo determinadas pelas seguintes classes: rara (r), dispersa (d), comum (c), abundante (a) e muito abundante $(\mathrm{ma})$. A Frequência $(\mathrm{F})$ refere-se à porcentagem de indivíduos de uma espécie em relação ao total de insetos coletados, sendo pouco frequente (PF), frequente (F) e muito frequente (MF). A constância representa a porcentagem de espécies presentes nos levantamentos efetuados, sendo dividida em categorias por Bodenheimer (1955), onde: a) Espécies constantes $(\mathrm{W})=$ presentes em mais de $50 \%$ das coletas; b) Espécies acessórias $(\mathrm{Y})=$ presentes em $25-50 \%$ das coletas; c) Espécies acidentais $(\mathrm{Z})=$ presentes em menos de $25 \%$ das coletas.

Com base no número total de indivíduos, obteve-se o índice de diversidade de Shannon (H) $(\mathrm{H}=-\Sigma \mathrm{pi} . \log \mathrm{pi}$, onde $\mathrm{pi}=\mathrm{ni} / \mathrm{N}$, onde, $\mathrm{ni}=$ densidade de cada grupo e $\mathrm{N}=\Sigma$ da densidade de todos os grupos), este pode variar de zero a cinco, onde os valores mais baixos correspondem à menor diversidade, indicando maior dominância de uma ou mais ordens na comunidade (Almeida et al., 2015). O índice de uniformidade de Pielou (e) $(\mathrm{e}=\mathrm{H} / \log \mathrm{S}$, com $\mathrm{H}=$ índice de Shannon e $\mathrm{S}$ = número de grupos) vai de zero a um, maiores valores indicam elevada homogeneidade e, portanto, maior diversidade (Ricklefs, 2003).

Os dados foram submetidos à análise de variância e os valores comparados pelo teste de Tukey a 5\% de probabilidade, com o auxílio do software estatístico SISVAR-ESAL (Ferreira, 2003). 


\section{Resultados e Discussão}

No somatório das oito coletas, quatro em cada época, identificaram-se 5.948 indivíduos, pertencentes a quinze ordens, sendo quatorze pertencente ao filo insecta e uma ao filo aracnida. $\mathrm{Na}$ época da estiagem foram identificados 4.160 indivíduos, distribuídos em dez ordens e na época chuvosa foram capturados 1.779 , pertencentes a quinze ordens (Figura 2). Apesar do incremento, nota-se que o elevado número de indivíduos na época da estiagem deveu-se basicamente a duas ordens, Diptera (3.135 indivíduos) e Hymenoptera (809 indivíduos).

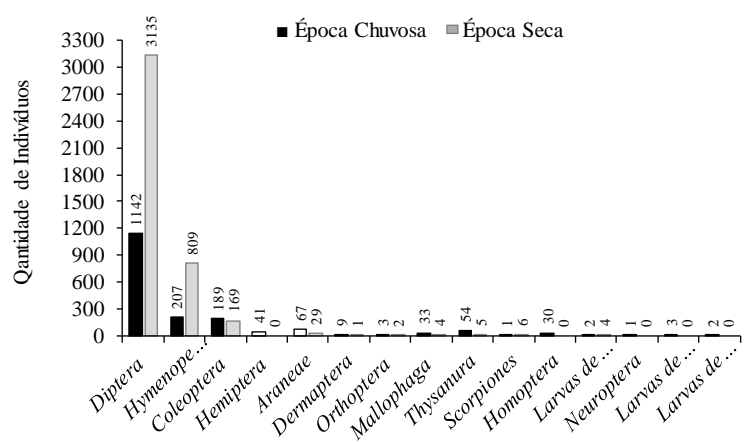

Figura 2. Distribuição do número de indivíduos da macrofauna em cultivo de palma forrageira de acordo com o grupo taxonômico em diferentes épocas do ano. Larvas de col.= Larvas de Coleópteros; Larvas de lep. $=$ Larvas de Lepidópteros; Larvas de dip. = Larvas de Dípteros.

$\mathrm{O}$ aumento no número de himenópteros se deve ao fato que este grupo se movimenta em seus ninhos no período de estiagem buscando alimento, outro fato que acarreta no aumento destes indivíduos no período de estiagem é a tolerância destes indivíduos a altas temperaturas (Bruchman et al., 2015). Almeida et al. (2015) associam a maior abundância de formigas no semiárido sua marcante interação no ambiente através do predatismo (a maioria de suas espécies) e mutualismo, na dispersão de sementes de espécies nativas e na grande capacidade de localização do alimento em épocas de estiagem mesmo distante de suas áreas usuais de forrageamento.

Doze das quinze ordens apresentaram acréscimo no número de indivíduos $(\mathrm{P}>0,05) \mathrm{em}$ função da chegada da época chuvosa, demonstrando que a maioria se prolifera com maior frequência a partir da chegada das águas. Possivelmente isso se deva a estratégia de sobrevivência das espécies, pois durante a época da estiagem o alimento e a água se tornam escassos; essa inconveniência associada à elevada temperatura e baixa umidade relativa do ar nas áreas semiáridas como no Seridó Potiguar, às vezes limitam a sobrevivência dos indivíduos jovens, tendo em vista que são mais sensíveis às condições do ambiente.

No solo do palmal na estação seca foram identificadas dez ordens obedecendo a sequência populacional para Diptera (3.135) > Hymenoptera (809) > Coleoptera (169) > Araneae (29) > Scorpiones (6) > Thysanura (5) $>$ Mallophaga (4) = Larvas de Coleópteros (4) > Orthoptera (2) > Dermaptera (1) indivíduos. Entretanto, na estação das águas, observou-se a presença de quinze ordens, prevalecendo a seguinte sequência: Diptera (1.142) > Hymenoptera (207) > Coleoptera (189) > Araneae (67) $>$ Thysanura (54) $>$ Hemiptera (41) $>$ Mallophaga (33) > Homoptera (30) > Dermaptera (9) > Orthoptera (3) = Larvas de lepídopteros (3) > Larvas de coleópteros (2) = Larvas de dípteros (2) > Scorpiones (1) = Neuroptera (1).

A redução da população de indivíduos das ordens Diptera e Hymenoptera na época chuvosa coincide com o período de reprodução dos sapos cururus da caatinga Bufo marinus Schneider 1799 , encontrados nas quatro coletas realizadas nesta época, onde foram identificados 121 anfíbios jovens desta espécie no interior das armadinhas. Em ambos os períodos de avaliação o solo estava sob uma camada de $5 \mathrm{~cm}$ de cobertura morta para reduzir as perdas hídricas do solo por evapotranspiração, possivelmente esta cobertura associada ao aumento da umidade edáfica na época chuvosa proporcionou um ambiente mais favorável à reprodução dos indivíduos da macrofauna, que obtiveram ganho de $50 \%$ na diversidade das ordens em relação a época da estiagem.

De acordo com Gondim et al. (2010) e Lima et al. (2010), em regiões tropicais e semiáridas há um aumento na macrofauna edáfica no período chuvoso, principalmente pelo favorecimento dos fatores climáticos, como temperatura, umidade edáfica e aumento da disponibilidade dos recursos alimentares. Entretanto, nota-se que os incrementos ocorreram na diversidade e na população de indivíduos da maioria das ordens, 
ampliando, consequentemente, as atividades exercidas no ambiente edáfico.

O aumento na diversidade beneficia expressivamente a cultura da palma forrageira tendo em vista que a elevação da umidade do solo associada à atividade intensa da fauna edáfica, principalmente na ciclagem de nutrientes aumenta a disponibilidade de nutrientes às plantas. Conforme Correia e Oliveira (2006), a macrofauna intensifica a ciclagem de nutrientes por meio da fragmentação e incorporação ao solo de detritos vegetais, promovendo aumento na disponibilidade de recursos para os microrganismos e mediando a transferência de solutos e particulados profundamente no perfil do solo. Associado a isso, os organismos promovem rearranjo físico da estrutura do solo contribuindo para o aumento do espaço poroso e, com efeito, na capacidade de infiltração de água e difusão dos gases da atmosfera edáfica.

Durante o período da estiagem (Tabela 1) as ordens Diptera, Hymenoptera, Coleoptera e Araneae foram superdominantes (SD), entretanto, na época das águas apenas as três primeiras apresentaram superdominância. No período chuvoso nota-se que um número maior de ordens apresentou padrão de dominância (D), dentre estas se destacam Hemiptera e Homoptera, ausentes no período da estiagem, demonstrando que a precipitação pluvial é um fator essencial para a reprodução de algumas ordens. Isto influenciou diretamente na abundância populacional da macrofauna, que na época das chuvas apresentou maior número de ordens raras.

Tabela 1 Dominância (D), Abundância (S), Frequência (F) e Constância (C) de indivíduos da macrofauna edáfica em cultivo de palma forrageira na época da estiagem e chuvosa no Seridó Potiguar

\begin{tabular}{lcccccccc}
\hline \multicolumn{1}{c}{ Classe/ } & D & D & S & S & F & F & C & C \\
\cline { 2 - 8 } \multicolumn{1}{c}{ Ordem Taxonômica } & EE & ECH & EE & ECH & EE & ECH & EE & ECH \\
\hline Diptera & SD & SD & sa & sa & SF & SF & W & W \\
Hymenoptera & SD & SD & sa & sa & SF & SF & W & W \\
Coleoptera & SD & SD & sa & sa & SF & SF & W & W \\
Hemiptera & - & D & - & ma & - & MF & - & W \\
Araneae & SD & D & sa & ma & SF & MF & W & W \\
Dermaptera & ND & D & r & c & PF & F & W & W \\
Orthoptera & ND & ND & d & d & PF & PF & Y & Y \\
Mallophaga & ND & D & c & c & F & F & W & W \\
Thysanura & ND & D & c & ma & F & MF & W & W \\
Scorpiones & D & ND & ma & r & MF & PF & W & Y \\
Homoptera & - & D & - & c & - & F & - & W \\
Larvas de col. & ND & ND & c & r & F & PF & W & Y \\
Neuroptera & - & ND & - & r & - & PF & - & Y \\
Larvas de lep. & - & ND & - & d & - & PF & - & Y \\
Larvas de dip. & - & ND & - & r & - & PF & - & Y
\end{tabular}

N. Ind. = Número de Indivíduos; $\mathrm{D}=$ Dominância; $\mathrm{S}=$ Abundância; $\mathrm{F}=$ Frequência; $\mathrm{C}=$ Constância; $\mathrm{EE}=$ Época da Estiagem; $\mathrm{ECH}=$ Época chuvosa, $\mathrm{SD}=$ Super Dominante; $\mathrm{D}=$ Dominante; ND = Não Dominante; as = Super abundante; ma = muito abundante; $\mathrm{a}=$ abundante $\mathrm{c}=$ comum $; \mathrm{r}=$ rara; $\mathrm{d}=$ dispersa; $\mathrm{SF}=$ Super Frequente; $\mathrm{MF}=$ Muito Frequente $; \mathrm{F}=$ Frequente; $\mathrm{W}=$ Constante; $\mathrm{Y}=$ Acessória; Larvas de col. = Larvas de Coleópteros; Larvas de lep. = Larvas de Lepidópteros; Larvas de dip. $=$ Larvas de Dípteros.

Quanto à frequência da macrofauna, na época chuvosa, a ordem Diptera destacou-se entre as demais por estar presente em formas distintas, como adultos e como larvas, com populações super e pouco frequente, respectivamente. Resultados semelhantes foram registrados por Machado et al. (2015), ao ressaltarem que a dinâmica dos dípteros na fauna edáfica é influenciada pela sazonalidade, com maior atividade dos respectivos indivíduos durante o período de maior precipitação pela maior disponibilização de alimento e adequabilidade de condições ambientais.

Azevedo et al. (2011) afirmam que, em geral, cada grupo de inseto responde de forma distinta às variações climáticas anuais. Os respectivos autores perceberam que os dípteros frugívoros e necrófagos predominaram na estação chuvosa e concluem que as condições de temperatura e precipitação influenciam na disponibilidade de alimento e abrigo para os representantes dessa ordem. 
Com relação à constância da macrofauna, em ambas as épocas, nove ordens foram classificadas como constantes, mas na época chuvosa houve uma superioridade de $500 \%$ nas ordens acessórias em relação à época da estiagem. Spiller et al. (2018) ressaltam que a comunidade edáfica é diretamente influenciada por fatores abióticos, como temperatura, umidade edáfica e do ar, assim como pela radiação solar, condicionados, principalmente pela sazonalidade e tipos de ambientes onde ocorrem. Tais parâmetros influenciam o ciclo de vida dos organismos pela disponibilidade de recursos, propiciando alterações na estrutura da comunidade (Manhães, 2011).

Os aspectos que caracterizam a macrofauna edáfica como uma eficaz ferramenta de bioindicação referem-se à capacidade e sensibilidade dos organismos em responderem às alterações no ambiente, na facilidade de serem amostrados usando metodologias de baixo custo, na existência de um amplo referencial bibliográfico e na identificação simples em nível de ordem e de família (Pinzón et al., 2014). Esses fatores tornam a macrofauna um eficiente indicador da qualidade edáfica, assim como das mudanças ambientais, principalmente nas áreas semiáridas do Brasil, onde as mudanças sazonais são mais nítidas.

Os índices de diversidade de Shannon $(\mathrm{H})$ e de uniformidade de Pielou (e) mostram-se adequados para o uso em ecologia do solo devido expressar a diversidade e uniformidade na abundância dos grupos taxonômicos em cada comunidade (Souza et al., 2017). Os baixos índices revelam situações de intensa dominância de reduzidos grupos taxonômicos, uma vez que, quanto maior o valor, menor o grau de incerteza, indicando que a diversidade amostral é alta (Balin et al., 2017).

$\mathrm{O}$ maior número de indivíduos relativos às ordens Diptera, Hymenoptera e Coleoptera resultou nos menores índices de Shannon $(\mathrm{H})$, principalmente no período da estiagem, chegando a 0,$12 ; 0,71$ e 1,39 (Tabela 2), enquanto que na época chuvosa os valores foram de 0,$19 ; 0,93 \mathrm{e}$ 0,97 , respectivamente. Esses resultados são confirmados pelos índices de uniformidade de Pielou (e) de 0,$03 ; 0,19$ e 0,38 para a época da estiagem e de 0,$06 ; 0,29$ e 0,30 na época das chuvas. $\mathrm{O}$ valor mais elevado de ambos os índices para a maioria das ordens na época das águas, demonstra a maior diversidade da macrofauna edáfica durante este período.

Tabela 2 Índice de diversidade de Shannon (H) e índice de uniformidade de Pielou (e) da macrofauna edáfica sob cultivo de palma forrageira nas épocas da estiagem (EE) e chuvosa (ECH) no Seridó Potiguar

\begin{tabular}{lcccc}
\hline \multirow{2}{*}{$\begin{array}{c}\text { Classe/ } \\
\text { Ordem taxonômica }\end{array}$} & H & H & e & e \\
\cline { 2 - 5 } & ECH & EE & ECH \\
\hline Diptera & 0,12 & 0,19 & 0,03 & 0,06 \\
Hymenopetera & 0,71 & 0,93 & 0,19 & 0,29 \\
Coleoptera & 1,39 & 0,97 & 0,38 & 0,30 \\
Hemiptera & - & 1,63 & - & 0,50 \\
Araneae & 2,15 & 1,42 & 0,59 & 0,44 \\
Dermaptera & 3,61 & 2,29 & 1,0 & 0,70 \\
Orthoptera & 3,31 & 2,77 & 0,91 & 0,85 \\
Mallophaga & 3,01 & 1,73 & 0,83 & 0,53 \\
Thysanura & 2,92 & 1,51 & 0,80 & 0,47 \\
Scorpiones & 2,84 & 3,25 & 0,78 & 1,0 \\
Homoptera & - & 1,77 & - & 0,9 \\
Larvas de col. & 3,01 & 2,95 & 0,83 & 0,54 \\
Neuroptera & - & 3,25 & - & 1,0 \\
Larvas de lep. & - & 2,95 & - & 0,85 \\
Larvas de dip. & - & 3,25 & - & 0,90 \\
\hline Larvas de col. = Larvas de Coleópteros; Larvas de lep. $=$ \\
Larvas de Lepidópteros; Larvas de dip. = Larvas de \\
Dípteros.
\end{tabular}

Resultados semelhantes foram apresentados por Almeida et al. (2015) ao obterem menor diversidade e número de grandes grupos taxonômicos da macrofauna do solo na época de estiagem no Curimataú paraibano. Para Souto et al. (2008), a maior diversidade de organismos edáficos é extremamente relevante pelo papel que estes exercem na ciclagem de nutrientes e no fluxo de energia do ecossistema, fator que se torna mais intenso na estação das chuvas.

Os resultados evidenciam o papel da precipitação pluvial como regulador das populações ecológicas no semiárido, desencadeando sazonalmente mudanças fisiológicas e morfológicas, tanto nas plantas, quanto nos organismos componentes da macrofauna edáfica.

\section{Conclusão}

Os grupos taxonômicos predominantes em ambas as épocas avaliadas foram Diptera, Hymenoptera e Coleoptera;

A macrofauna no cultivo de palma forrageira é mais abundante na época da estiagem e mais diversificada na época chuvosa; 
A dinâmica da macrofauna é influenciada pela precipitação pluviométrica que age como reguladora destas populações no solo.

\section{Referências}

Aita, C.; Giacomini, S. J.; Ceretta, C. A. Decomposição de nutrientes dos resíduos culturais de adubos verdes. In: Lima Filho, O. F.; Ambrosano, E. J.; Rossi, F.; Donizeti Carlos, J. A. Adubação verde e plantas de cobertura no Brasil: Fundamentos e Prática, 2014. cap. 6, p. 227-264.

Almeida, M. A. X.; Souto, J. S.; Andrade, A. P. Sazonalidade da macrofauna edáfica do Curimataú da Paraíba, Brasil. Revista Ambiência, v.11, n.2, p.393-407, 2015. https://revistas.unicentro.br/index.php/ambiencia/article/v iew/2613/pdf

Alvares, C. A.; Stape, J. L.; Sentelhas, P. C.; Gonçalves, J. L. M.; Sparovek, G. Köppen's climate classification map for Brazil. Meteorologische Zeitschrift, v.22, n.6, p.711728, 2013. https://dx.doi.org/10.1127/09412948/2013/0507

Antoniolli, Z. I.; Conceição, P. C.; Bock, V.; Port, O.; Silva, R. F. Método alternativo para estudar a fauna do solo. Ciência Florestal, v.16, n.4, p.407-417,

2006. http://dx.doi.org/10.5902/198050981922

Azevedo, F. R.; Moura, M. A. R.; Arrais, M. S. B.; Nere, D. R. Composição da entomofauna da floresta nacional do araripe em diferentes vegetações e estações do ano. Revista Ceres, v.58, n.6, p.740-748, 2011. http://dx.doi.org/10.1590/S0034-737X2011000600010

Balin, N. M.; Bianchini, C.; Ziech, A. R. D.; Luchese, A. V.; Alves, M. V.; Conceição, P. C. Fauna edáfica sob diferentes sistemas de manejo do solo para produção de cucurbitáceas. Revista Scientia Agraria, v.18, n.3, p.74-84, 2017. http://dx.doi.org/10.5380/rsa.v18i3.52133

Bruchman, G. E. C. et al. Análise sazonal da entomofauna associada à vegetação no aterro da souza cruz, RS, Brasil. Revista Jovens Pesquisadores, v.5, n.1, p.25-39, 2015. http://dx.doi.org/10.17058/rip.v5i1.5748

Bodenheimer, F. S. Precis d'ecologieanimale. Paris: Payot, 1955. 315 p.

Correia, M. E. F.; Oliveira, L. C. M. Importância da fauna de solo para a ciclagem de nutrientes.
In: Aquino, A. M.; Assis, R. L. (Org.). Processos biológicos no sistema solo-planta: Ferramentas para uma agricultura sustentável. $1^{\text {a }}$ ed. Brasília, DF: Embrapa Informação Tecnológica, 2006, v.1, p.77-99.

Ferreira, D.F. SISVAR 4.6 Sistema de análises estatísticas. Lavras: UFLA, 2003. 32p.

Galvão Júnior, J.G.B.; Silva, J.B.A.; Morais, J.H.G.; Lima, R.N. Palma forrageira na alimentação de ruminantes: Cultivo e utilização. Acta Veterinaria Brasilica, v.8, n.2, p.78-85, 2014. http://dx.doi.org/10.21708/avb.2014.8.2.3490

Gondim, S. C.; Souto, J. S.; Cavalcante, L. F.; Araújo, K. D.; Rodrigues, M. Q. Biofertilizante bovino e salinidade da água na macrofauna do solo cultivado com maracujazeiro amarelo. Revista Verde de Agroecologia de Desenvolvimento Sustentável, v.5, n.2, p.1524, 2010. http://dx.doi.org/10.18378/rvads.v5i2.272

Laroca, S.; Mielke, O. H. H. Ensaio sobre ecologia de comunidade em sphingidae na serra do mar, Paraná-BR, (Lepidoptera). Revista Brasileira de Biologia, v.35, n.1, p.1-19, 1975. http://aims.fao.org/serials/c_16b56a41

Lima, S. S.; Aquino, A. M.; Leite, L. F. C., Velásquez, E. E.; Lavelle, P. Relação entre macrofauna edáfica e atributos químicos do solo em diferentes agroecossistemas. Pesquisa Agropecuária Brasileira, v.45, n.3, p.322-331, $2010 . \quad$ http://dx.doi.org/10.1590/S0100204X2010000300013

Machado, D. L.; Pereira, M. G.; Correia, M. E. F.; Diniz, A. R.; Menezes, C. E. G. Fauna edáfica na dinâmica sucessional da mata atlântica em floresta estacional semidecidual na bacia do rio Paraíba do Sul - RJ. Ciência Florestal, v.25, n.1, p.91-106, 2015. http://dx.doi.org/10.1590/1980509820152505091

Manhães, C. M. C. Caracterização da fauna edáfica de diferentes Coberturas vegetais no norte do estado do Rio de Janeiro, Brasil. 2011. 71 f. Dissertação (Mestrado em Produção Vegetal) - Universidade Estadual do Norte Fluminense Darcy Ribeiro, Campos dos Goytacazes, 2011.

Marques, D. M. Silva, A. B.; Silva, L. M.; Moreira, E. A.; Pinto, G. S. Macrofauna edáfica em diferentes coberturas vegetais. Bioscience Journal, v.30, n.5, p.1588-1597, 2014. 
http://www.seer.ufu.br/index.php/biosciencejournal/articl e/view/22926

Martins, L.F.; Pereira, J.M.; Tonelli, M.; Baretta, D. Composição da macrofauna do solo sob diferentes usos da terra (cana-de-açúcar, eucalipto e mata nativa) em Jacutinga (MG). Revista Agrogeoambiental, v.9, n.1, p.11-22, 2017. http://dx.doi.org/10.18406/2316$\underline{1817 \mathrm{v} 9 \mathrm{n} 12017913}$

Pinzón, S. T.; Rousseau, G. X.; Piedade, A. R.; Celentano, D.; Zelarayán, M. L. C.; Braun, H. La macrofauna del suelo como indicadora de degradación de bosques ribereño en la amazonia oriental brasileira. Revista de la Facultad de Agronomía, v.114, n.1, p.49-60, 2014. http://hdl.handle.net/10915/47307

Ramos, J. P. F.; Souza, J. T. A.; Santos, E. M.; Pimenta Filho, E. C.; Ribeiro, O. L. Crescimento e Produtividade de Nopalea cochenillifera em função de diferentes densidades de plantio em cultivo com e sem capina. Revista Electrónica de Veterinária, v. 18, n.8, p. $1-12, \quad 2017$. http://www.veterinaria.org/revistas/redvet/n080817/0817 04.pdf

Ricklefs, R. E. A Economia da Natureza. Rio de Janeiro-RJ: Guanabara Koogan, 2003. 542p.

Santos, D. C.; Lira, M. A.; Dubeux Júnior, J. C. B.; Santos, M. V. F.; Mello, A. C. L. Recomendação de adubação para a palma forrageira. In: Cavalcanti, F. J. A. (Ed.) Recomendações de adubação para o estado de Pernambuco: $2^{\mathrm{a}}$ Aproximação. Instituto
Agronômico de Pernambuco, Recife-PE, 2008, p. 178

Silveira Neto, S.; Haddad, M. L.; Moraes, R. C. B.; Lai Reyes, A. E. ANAFAU - análise faunística. Piracicaba-SP, Editora ESALQ, 2005. 38 p. Disponível em: < http://www.esalq.usp.br >. Acesso em: 18 out. 2017.

Simpson, J. E.; Slade, E.; Riutta, T.; Taylor, M. E. Factor saffecting soil fauna feeding activity in a fragment ed low land temperate deciduous wood land. PlosOne, v.7, n.1, p.1-6, 2012. https://doi.org/10.1371/journal.pone.0029616

Souto, P. C.; Souto, J. S.; Miranda, J. R. P.; Santos, R. V.; Alves, A. R. Comunidade microbiana e mesofauna edáficas em solo sob Caatinga no Semiárido da Paraíba. Revista Brasileira de Ciência do Solo, v.32, n.1, p.151160, 2008. http://dx.doi.org/10.1590/S0100$\underline{06832008000100015}$

Souza, J. T. A.; Oliveira, S. J. C.; Nápoles, F. A. M.; Souza, M. S.; Medeiros, M. R. Diversidade de macrofauna edáfica em diferentes ambientes de cultivo no agreste da Paraíba, Brasil. Revista de Agricultura Neotropical, v.4, n.3, p.55-60, 2017.

https://periodicosonline.uems.br/index.php/agrineo/article /view/1681/1556

Spiller, M. S.; Spiller, C.; Garlet, J. Arthropod bioindicators of environmental quality. Agro@mbiente on-line, v.12, n.1, p.41-57, 2018. http://dx.doi.org/10.18227/19828470ragro.v12i1.4516 